\title{
Pressure drop characteristics of vertically upward flow in inclined rod bundles
}

\author{
K. Zhang a , W.X. Tian a,, , Y.D.Hou ${ }^{\text {a }}$, Y.P. Zhang a , S.Z. Qiu ${ }^{\text {a }}$, G.H. Su ${ }^{\text {a }}$ \\ ${ }^{a}$ School of Nuclear Science and Technology, Xi'an Jiaotong University, 28 Xianning West Road, \\ Xi'an 710049, China
}

\begin{abstract}
An experimental and theoretical research has been carried out for vertically upward two-phase flow of air-water across staggered rod bundles having inclination angles of 0,45 and 90 degrees. New correlations for single-phase pressure drops in rod bundles for various inclination angles were developed. The single-phase frictional resistance in the vertical flow was found to have a minimal effect on the total flow resistance in the inclined flow. Based on the single-phase pressure drop data, a new superposition model was proposed and verified to be successful in predicting both the present data and the experimental data in previous experiments of other researchers. The two-phase friction multiplier in the inclined rod bundle, which decreased with increasing mass velocity at a given value of Martinelli parameter, could be fit well in terms of Martinelli parameter and the defined dimensionless mass velocity. In addition, the two-phase friction multiplier first increased and then decreased with increasing Martinelli parameter at a given value of mass velocity for $G<200 \mathrm{kgm}^{-2} \mathrm{~s}^{-1}$. The new correlations developed for two-phase friction multipliers were successful in predicting the two-phase pressure drop data in the inclined rod bundle.
\end{abstract}

Key words: pressure drops; a new superposition model; inclined rod bundle; Martinelli parameter, two-phase friction multiplier

\section{Introduction}

Shell-side pressure drops play an important role in the design and operation of heat exchangers such as steam generators, condensers and evaporators. Specially, as the primary side pressure boundary in nuclear power plants, the integrity of U-tube bundles in a steam generator must be maintained during its operation. Besides, the vibration and failure of U-tube bundles may result in a release of contaminative primary coolant to the conventional island. As a result, a large

\footnotetext{
${ }^{*}$ Corresponding author. Tel.: +86 02982668325.

E-mail address: wxtian@mail.xjtu.edu.cn (W.X. Tian).
} 
number of theoretical investigations [1-4] for a comprehensive understanding of three-dimensional thermohydraulic distribution in steam generators have been carried out. However, experiments on pressure drops in the secondary of U-tube bundles in a steam generator have been performed, since difficulty lies both in fabrication and measuring techniques due to complex geometries. In the case of flow across U-tube bundles in steam generators, the bent part of U-tube bundles could be divided into several parts [5], i.e. straight tube bundles having different inclination angles. Then, pressure drops of flow across U-tube bundles could be calculated by the integration of pressure drops in flow across tube bundles having various inclined angels.

\subsection{Single-phase experiments in inclined rod bundle}

Several previous investigations have been conducted on hydrodynamics of the single-phase flow in inclined rod bundles. The earliest published pressure drop data for flow across inclined rod bundles were proposed by Kazakevich [6]. He measured pressure drops of air flow across one to seven rows of rods for inclination angles of 90, 60, 45 and 30 degrees. The inclination angle, $\theta$, represents the angle between the flow direction and the rod axis, as shown in Fig.1. The stream Reynolds number in a six in-line and eight staggered rod arrangements ranged between 7,000 and 100,000. However, the data were not actual pressure drops in inclined rod bundles because the pressure taps failed to avoid the effects of sudden enlargement and contraction of flow area when air flowed into and out of the inclined rod bundles. Boettgenbach [7] obtained pressure drop data for air flow across inclined rod bundles in a square array. The inclination angles were 90, 75, 60, 45 and 30 degrees. Reynolds number ranged between 55,000 and 550,000. However, pressure drop data scattered largely due to the localized measuring techniques employed in the experiments. Möller [8] performed experiments on pressure drops of air flow across inclined rod bundles in an irregular array. The inclination angles were 90,60 and 45 degrees. He also developed a rod arrangement independent, two-dimensional flow resistance correlation using a superposition model. However, only a few data points at Reynolds number of 1,100 were obtained due to the limitations of the air blower system in his experiments. In addition, several data points were questionable because the array geometry was not well controlled between different flow inclination angles. Groehn [9] made pressure drop measurements of air flow across one to ten 
rows of rods. The inclination angles were $90,75,60,45,30$ and 15 degrees. However, similar to Kazakevich [6], the measured data failed to avoid the effects of sudden enlargement and contraction of flow area. Todreas [10] made extensive experiments for water flow across inclined rod bundles in a square array. The inclination angles were 90, 60, 45, 30 and 0 degrees. Reynolds number ranged between 1,000 and 27,000. Two superposition models were proposed to predict the single-phase pressure drop data. However, since form drag dominated all flow inclination angles, the models were verified inconclusive for turbulent flow. Choi el al. [11] measured pressure drops of water flow across triangular and rotated triangular tube arrays. The inclination angles were 30 , 45, 60 and 90 degrees. The pressure drop predicted by modified Idel'chik [12] correlations agreed well with the experimental data.



Fig.1. The decomposition of velocity in the inclined flow.

\subsection{Single-phase superposition models}

In order to accurately predict single-phase pressure drops in inclined rod bundles, several superposition models have been proposed. The calculations for single-phase pressure drops of flow across inclined rod bundles in previous investigations were usually based on an assumption. The assumption was that the inclined flow velocity, $\langle V\rangle$, could be decomposed into the vertical component, $V_{/ /}(\theta)$, and the horizontal component, $V_{\perp}(\theta)$, as shown in Fig. 1. Then the flow 
resistance in the inclined rod bundle, $\langle R\rangle$, could be calculated by the following expression,

$$
\langle R\rangle=\sqrt{\mathbf{R}_{/ /}^{2}(\theta)+\mathbf{R}_{\perp}^{2}(\theta)}
$$

Here, $R_{/ /}(\theta)$ and $R_{\perp}(\theta)$ were separately flow resistances in the direction of the parallel flow and the crossflow, which could be given by,

$$
\begin{aligned}
& R_{/ /}(\theta)=C_{/ /}(\theta) \frac{1}{\mathrm{D}_{V}} \frac{\rho_{F} V_{/ /}^{2}(\theta)}{2} \\
& R_{\perp}(\theta)=C_{\perp}(\theta) \frac{1}{\mathrm{D}_{V}} \frac{\rho_{F} V_{\perp}^{2}(\theta)}{2}
\end{aligned}
$$

Here, the parallel flow superposition factor, $g(\theta)$, and the crossflow superposition factor, $h(\theta)$, were defined as:

$$
\begin{aligned}
& \mathrm{g}(\theta)=R_{/ /}(\theta) / R_{/ /}\left(0^{\circ}\right) \\
& \mathrm{h}(\theta)=R_{\perp}(\theta) / R_{\perp}\left(90^{\circ}\right)
\end{aligned}
$$

Here, $R_{/ /}\left(0^{\circ}\right)$ and $R_{\perp}\left(90^{\circ}\right)$ were flow resistances in the direction of the parallel flow and the crossflow based on the inclined flow velocity.

Table 1 summarized and compared the previous superposition models. Todreas [10] indicated that all the models in Table 1 were inconclusive for turbulent flow in inclined rod bundles.

Table1 Superposition models

\begin{tabular}{|c|c|c|c|c|}
\hline Model & $g(\theta)$ & $h(\theta)$ & Constants & References \\
\hline 1 & $\frac{\cos \theta}{(\cos 0.9 \theta)^{2}}$ & $(\sin \theta)^{1.9}$ & ----- & Boettgenbach [7] \\
\hline 2 & $(\cos \theta)^{2-n}$ & $(\sin \theta)^{2-m}$ & $n=0.25$ & Liles [13] \\
\hline 3 & $\cos \theta$ & & $\eta(0)=0.15$ & \\
& & & $\eta(30)=0.60$ & Coëffe and Todreas \\
& & & $\eta(45)=0.76$ & [14] \\
& & & $\eta(60)=0.94$ & \\
\hline
\end{tabular}




\begin{tabular}{|c|c|c|c|c|}
\hline & & & $\eta(90)=1.00$ & \\
\hline 4 & $\left(\cos ^{2} \theta+\frac{1}{\delta^{2}} \sin ^{2} \theta\right)^{\frac{1-n}{2}} \cos \theta$ & $(\sin \theta)^{2-m}$ & $m=0.15$ & Todreas [10] \\
\hline 5 & $(\cos \theta)^{n+1}$ & $(\sin \theta)^{m+1}$ & $n=0$ & \\
\hline & & & $m=0.4$ & Todreas [10] \\
\hline
\end{tabular}

1.3 Two-phase experiments in inclined rod bundles

Few experiments have been carried out on two-phase flow across inclined rod bundles. Barasch [15] performed a high void fraction flow experiment in a vertical array one row deep and 24 rows wide. He found that the inclusion of rod array reduced the phase separation in the test duct without rod array. Benchmarking void and liquid velocity distributions were also obtained. Osakabe and Adachi [16] measured pressure drops of air-water two-phase flow across inclined rod bundles in a square arrangement. The inclination angles were 0,15 , and 30 degrees. They found that predictions calculated by the homogeneous model agreed well with the pressure drop data when the inclination angle was 0 degree, while the drift flux model was the most accurate model to predict the data when the inclination angle was 30 degree. And when the inclination angle was 15 degree, data fell between predictions using the homogenous model and the drift flux model. It was worth noting that the test sections were inclined to retain the rod axis vertical. Todreas [10] investigated velocity distributions of air-water two-phase flow across inclined rod bundles. $\mathrm{He}$ found that bubbles much smaller than the rod diameter migrated into recirculating vortices and moved along the rod axis, while large deformed bubbles moved across rods. These movements of bubbles would affect the drag force of two-phase flow. However, two-phase friction pressure drop data were not published in the experiments. Serizawa et al. [5] carried out experimental and numerical analyses on vertically upward air-water bubbly two-phase flow across inclined rod bundles in staggered and in-line arrangements. They found that inclination angles of rod bundles affected significantly phase distributions.

It is seen from the literature review that none of previous superposition models could be successful in predicting single-phase pressure drops in inclined rod bundles. Besides, whether 
pitch-to-diameter ratios affect pressure drops in inclined rod bundles has not been verified. As a result, new accurate correlations are needed to predict pressure drops of single-phase flow across U-tube bundles in steam generators. In the case of two-phase flow, there were no published pressure drop data. Therefore, the purpose of present study is to carry out experiments to obtain pressure drops in an equilateral triangular inclined rod bundles. New correlations for single-phase pressure drops and two-phase multipliers were developed. In addition, a new superposition model was developed to predict single-phase pressure drops in inclined rod bundles.

\section{Test facility description}

The test loop is shown in Fig. 2. Compressed air with a maximum flow rate of $13 \mathrm{~m}^{3} / \mathrm{min}$ was measured by two vortex flowmeters at high gas flow rates, and with a procession vortex flowmeter at low flow rates. Water stored in the tank was delivered by the centrifugal pump with a capacity of $30.0 \mathrm{t} / \mathrm{h}$. The air-water mixture traveled up through the rectangular test section with a horizontal rod bundle inside. Then the mixture returned into the water tank. A copper-constantan thermocouple and three Rosemount pressure transducers were installed in the branch line contained vortex flowmeters. They were used for measuring the temperature and pressure of air.

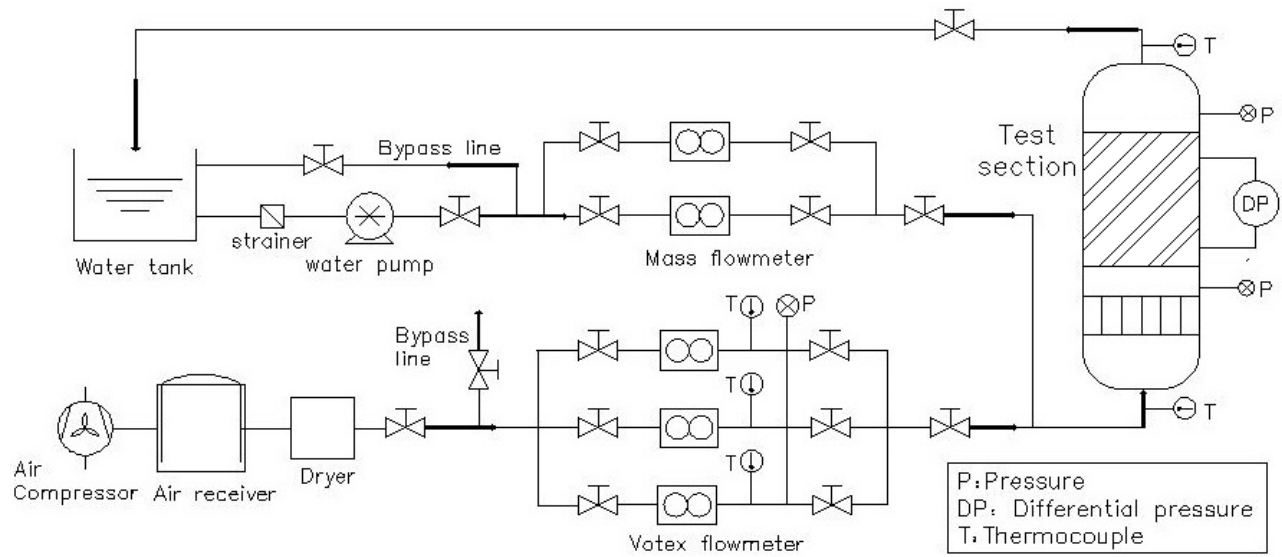

Fig.2. Test loop.

There are three test sections. Fig. 3 represents the vertical rod bundle enclosed by a circular duct with an inner diameter of $75.44 \mathrm{~mm}$ where seven heater rods located in an equilateral triangular array. The pitch-to-diameter ratio was 1.424. The upper and lower support plates with a thickness of $30.0 \mathrm{~mm}$ were installed as SP1 and SP2 as shown in Fig. 3. A flow straightener was placed below the rod bundle to obtain a fully developed flow condition in the test section. 
Rosemount pressure transducers measuring the pressures of the flow in the circular duct were located in the side walls (Pressure tap 1, 4). A Rosemount pressure transducer with a range of $-6.22-6.22 \mathrm{kPa}$ was used to obtain the differential pressure drop in the bare vertical rod bundle. Two copper-constantan thermocouples were used to measure the inlet and outlet temperatures of working fluids in the test section.

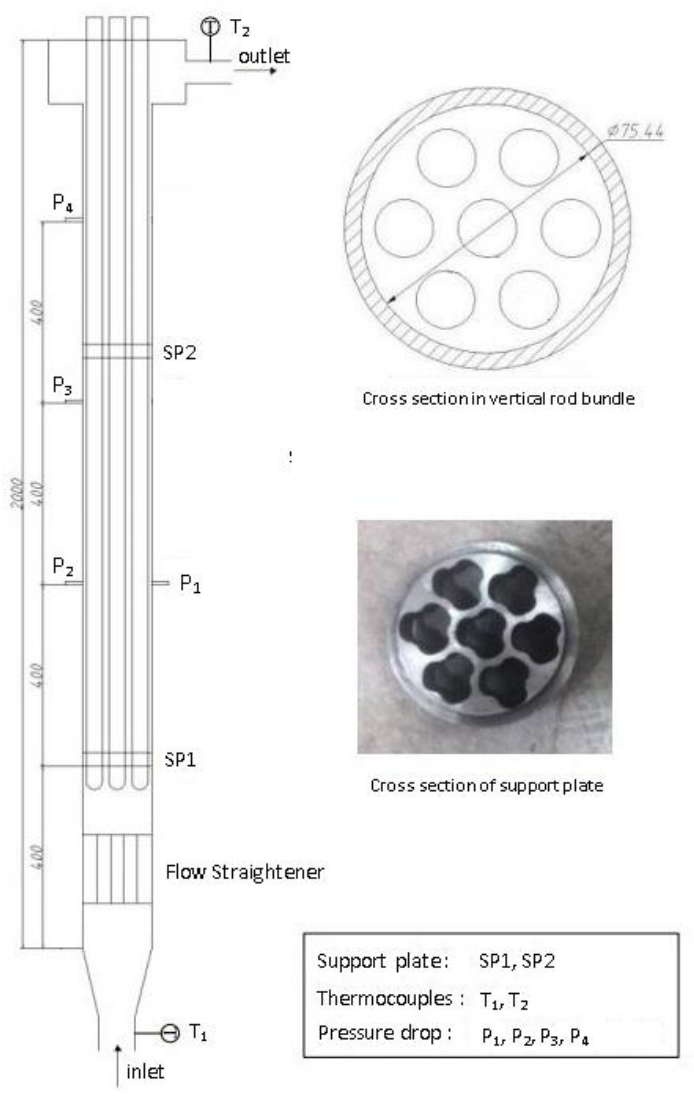

Fig.3. Vertical test section.

Fig. 4 and Fig. 5 separately represent the horizontal rod bundle and inclined rod bundle, which were both enclosed by a rectangular duct with a $99.56 \times 250.0 \mathrm{~mm}$ cross-section. The inclinations were 90 and 45 degrees, respectively. The horizontal rod bundle was fitted with 16 rows of rods in an equilateral triangular array, with 3 rods in the odd row and 4 rods in the even row. For the inclined rod bundle, 25 rows of rods were arranged in the similar layout. The diameter of rods and the pitch-to-diameter ratio were the same for the rod bundles having inclination angles of 90,45 and 0 degrees. To reduce the bypass leakage and minimize the wall effect, two half-rods were attached to side walls in each odd row. In order to obtain a fully developed flow condition before working fluids flowed into the rod bundle, a flow straightener 
was located $200 \mathrm{~mm}$ from the bottom of the rod bundle. The flow direction of the single-phase flow could be verified to be perpendicular to the horizontal rod bundle according to the result of CFD. Rosemount pressure transducers were used for measuring pressures of the flow across 10 rows of rods in the test section. They were located in side walls of the test section (pressure tap 1, 4). To minimize the effects of sudden enlargement and contraction of flow area on the pressure

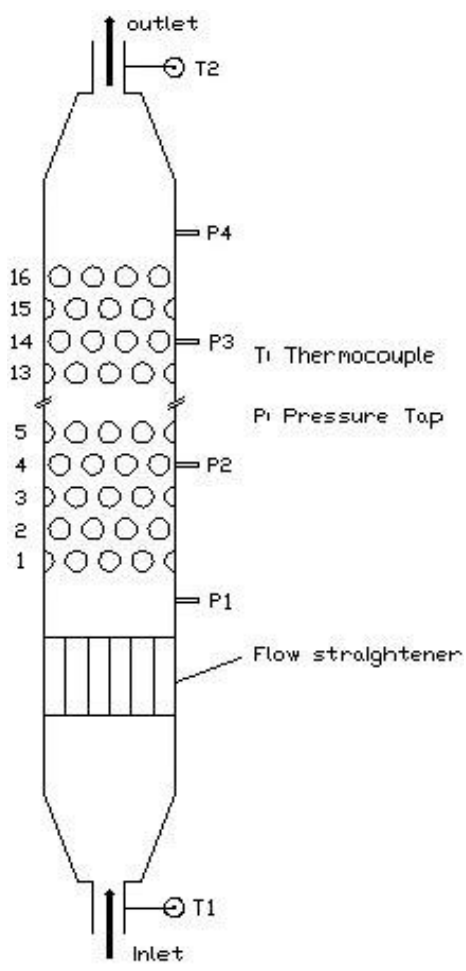

(a) side view

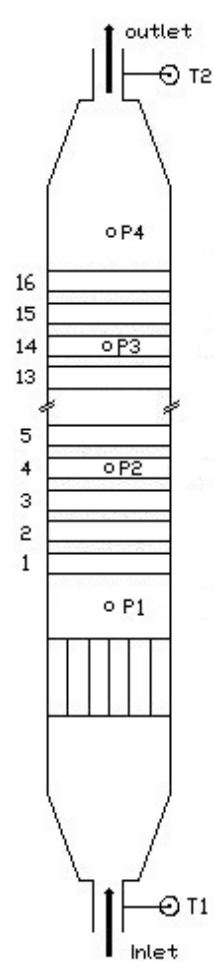

(b) front view

Fig.4. Horizontal test section. 


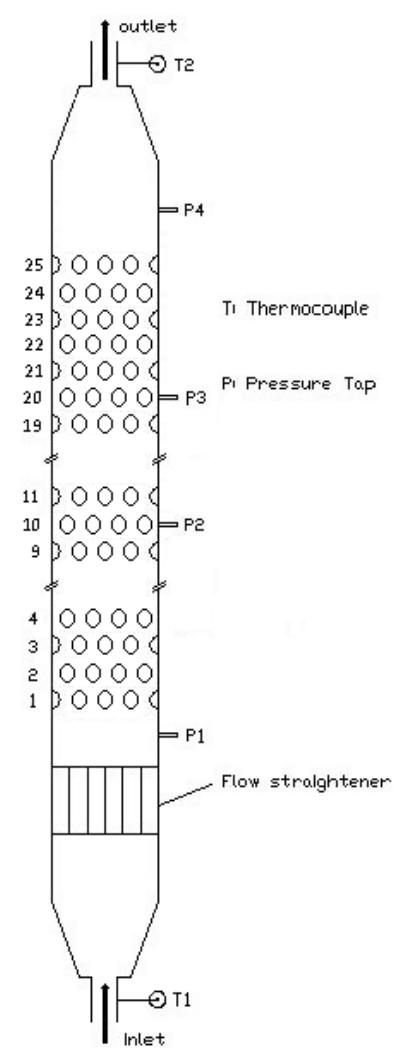

(a) side view

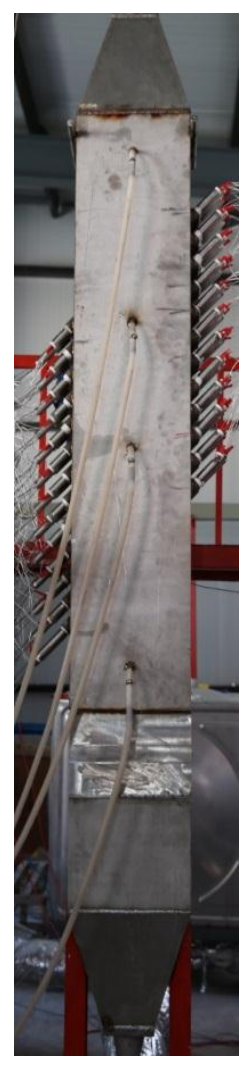

(b) front view

Fig.5. Inclined test section.

drop in the rod bundle when working fluids flowed into and out of the rod bundle, Rosemount pressure transducers with a range of -6.22-6.22 $\mathrm{kPa}$ were connected to pressure taps (pressure tap 2, 3) to obtain pressure drops in horizontal and inclined rod bundles. The detailed description of position for pressure taps is shown in Fig. 4.and Fig. 5. The inlet and outlet temperatures of working fluids in the test sections were measured with two copper-constantan thermocouples. A National Instruments acquisition system and an interface panel based on LabVIEW were employed to obtain and save the test data.

\section{Experimental methods and conditions}

\subsection{Test procedures}

Pressure drops of single phase water in three test sections were first measured. Then the total two-phase pressure drops in the inclined rod bundle were obtained. In order to obtain the two-phase multiplier in the inclined rod bundle, the total mass velocity was set at a specified value and the air quality was increased by controlling valves in the test loop. After reaching a steady 
condition, signals from all transducers were recorded.

\subsection{Experiment conditions}

In single-phase pressure drop tests, mass velocities and Reynolds numbers for rod bundles are shown in Table 2. The Reynolds numbers are defined as:

Table 2 Single-phase experiment condition

\begin{tabular}{|c|c|c|c|c|}
\hline Test section & $\begin{array}{c}\text { Inclination } \\
\text { angle } \\
(\text { Degree })\end{array}$ & $\begin{array}{c}\text { Mass velocity } \\
\left(\mathrm{kgm}^{-2} \mathrm{~s}^{-1}\right)\end{array}$ & $\begin{array}{c}\text { Equivalent } \\
\text { diameter }(\mathrm{m})\end{array}$ & Reynolds number \\
\hline Vertical rod bundle & 0 & $402-2450$ & $\mathrm{D}$ e & $5,400-126,349$ \\
\hline $\begin{array}{c}\text { Horizontal rod } \\
\text { bundle }\end{array}$ & 45 & $57-1051$ & $\mathrm{~d}$ & $1,397-44,923$ \\
\hline Horizontal rod \\
bundle
\end{tabular}

$\mathrm{Pe}_{/ /}=\frac{\rho_{F} V_{/ /} D_{e}}{\mu_{F}}$

$\mathrm{Re}_{\perp}=\frac{\rho_{F} V d}{\mu_{F}}$

$\langle\mathrm{Pe}\rangle=\frac{\rho_{F}\langle\mathrm{~V}\rangle d}{\mu_{F}}$

Here, $\mathrm{Pe}_{/ /}, \mathrm{Pe}_{\perp}$ and $\langle\mathrm{Pe}\rangle$ are separately the Reynolds number in the vertical, horizontal and inclined rod bundle. $\rho_{F}$ and $\mu_{F}$ are the density and the dynamic viscosity of water. $D_{\mathrm{e}}$ is the hydraulic diameter in the vertical rod bundle and d is the diameter of rods. $V_{/ /}$is the mean axial velocity in the vertical rod bundle. $V_{\perp}$ is the maximum velocity in the horizontal rod bundle. $\langle V\rangle$ is the crossflow mainstream velocity and can be calculated using following expressions [10].

$$
\langle V\rangle=\frac{\langle V\rangle_{\infty}}{\delta \cdot \Upsilon}
$$


Here, $\langle\mathrm{V}\rangle_{\infty}$ is the inlet velocity of single phase flow in the inclined test section. $\gamma$ and $\delta$ are the volume porosity and the crossflow mainstream porosity calculated based on model A [10] as shown in Fig. 6.

$$
\begin{aligned}
& \Upsilon=\frac{S_{T} S_{L}-\pi d^{2} / 4}{S_{T} S_{L}} \\
& \delta=\frac{\left(S_{T}-d\right) S_{L}}{S_{T} S_{L}}
\end{aligned}
$$

Here, $S_{\mathrm{T}}$ and $\mathrm{S}_{\mathrm{L}}$ are the transverse and longitudinal pitch in the horizontal rod bundle.

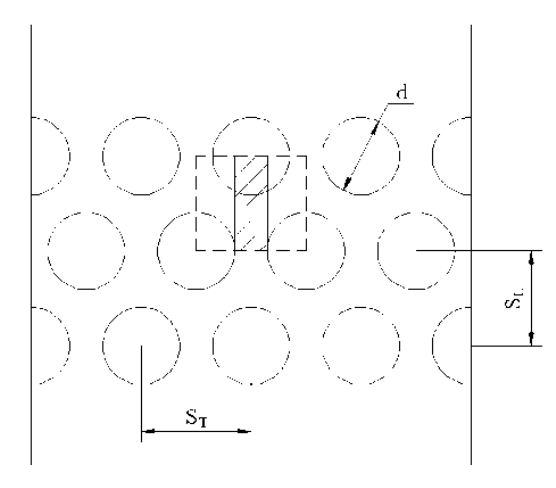

Fig.6. Crossflow mainstream porosity model.

In air-water two-phase pressure drop tests, the total mass velocity with a range from 80 to 500 $\mathrm{kg} /\left(\mathrm{m}^{2} \mathrm{~s}\right)$ was kept constant as the air quality changed from $9 \times 10^{-4}$ to 0.27 . The pressure in all tests was slightly higher than atmospheric pressure, which ranged between 115 and $231 \mathrm{kPa}$. The mixture temperature in the test section varied from 11.5 to $35.7^{\circ} \mathrm{C}$.

\subsection{Uncertainty analysis}

Uncertainties for the majority of the experimental data were mainly produced by data measurement errors caused by the instrumentation and collection errors or the data acquisition system. Assuming the instrumental error was uniformly distributed, the standard uncertainty $u(a)$ could be estimated using the following expression [17],

$$
u(a)=\left(\Delta_{i n s}+\Delta_{a c q}\right) / \sqrt{3}
$$

where $\Delta_{\mathrm{ins}}$ and $\Delta_{\mathrm{acq}}$ are separately the instrument error and the acquisition system error. The maximum error of the National Instruments acquisition system is $0.02 \%$. As a result, all the data uncertainties calculated based on the expression are shown in table 3. 
Table 3 Instrumentation list

\begin{tabular}{|l|c|c|c|}
\hline \multicolumn{1}{|c|}{ Instrument Function } & Range & Maximum Permissible & Data \\
uncertainty
\end{tabular}

\section{Experimental results and discussion}

\subsection{Single-phase friction factor data}

The measured single-phase pressure drops between taps 2 and 3 in three test sections can be used to compute single-phase pressure loss coefficients as follows [11, 18, 19],

$$
\begin{aligned}
& C_{/ /}=\frac{2 \Delta P_{/ /}^{F} D_{e}}{\rho_{\mathrm{F}} V_{/ /}^{2} \mathrm{~L}} \\
& C_{\perp}=\frac{2 \Delta P_{\perp}^{F}}{N \rho_{\mathrm{F}} V_{\perp}^{2}} \\
& \langle C\rangle=\frac{2\langle\Delta \mathrm{P}\rangle_{F}}{M \rho_{\mathrm{F}}\langle V\rangle^{2}}
\end{aligned}
$$


Here, $\Delta P_{/ /}^{F}, \Delta P_{\perp}^{F}$ and $\langle\Delta \mathrm{P}\rangle_{F}$ are separately the measured pressure drops between taps 2 and 3 in the vertical, horizontal and inclined test section. $L$ is the distance between taps 2 and 3. $N$ and $M$ are the numbers of rod rows between pressure taps in the horizontal and inclined rod bundles.

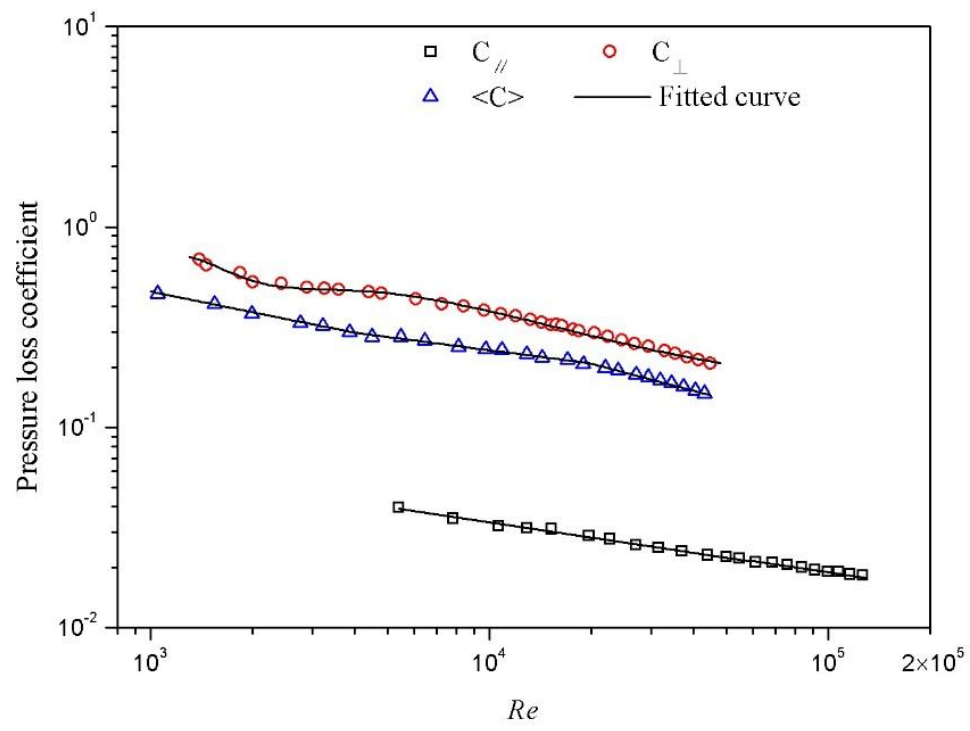

Fig.7. Single-phase pressure loss coefficients in rod bundles.

Fig. 7 represents the comparison of single-phase pressure loss coefficients in rod bundles. It is worth noting that the pressure loss coefficient increases with increasing the inclination angle. In addition, the pressure loss coefficient in the vertical rod bundle is much smaller compared with that in the horizontal and inclined rod bundles. For the parallel flow, there is no form drag since that the flow area is constant. However, for the horizontal flow and the inclined flow, the total pressure loss consists of both the frictional resistance and the form drag. It can be concluded that the frictional resistance has a minimal effect on the total flow resistance for the inclined flow. The single-phase pressure loss coefficient data can be fit well using the following expressions:

$$
\begin{aligned}
& C_{/ /}=0.335 / \mathrm{Re}^{0.25} \\
& C_{\perp}=0.142+\frac{3480}{\operatorname{Re}_{\perp}}-\frac{1.3 \times 10^{7}}{\operatorname{Re}_{\perp}^{2}}+\frac{2.08 \times 10^{10}}{\operatorname{Re}_{\perp}^{3}}-\frac{1.11 \times 10^{13}}{\operatorname{Re}_{\perp}^{4}}
\end{aligned}
$$

$$
\langle C\rangle= \begin{cases}4.98 /\langle\mathrm{Pe}\rangle^{0.34} & 10^{3}<\langle\mathrm{Pe}\rangle<4 \times 10^{3} \\ 1.84 /\langle\mathrm{Pe}\rangle^{0.22} & 4 \times 10^{3} \leq\langle\mathrm{Pe}\rangle<2 \quad \rtimes 0^{4} \\ 17.9 /\langle\mathrm{Pe}\rangle^{0.45} & 2 \times 10^{4} \leq\langle\mathrm{Pe}\rangle<4.3 \quad \exists 0^{4}\end{cases}
$$


Eqs. (16) (18) are in good agreement with the present data with a maximum deviation of $\pm 4.0 \%$.

\subsection{Single-phase superposition model}

The literature review of superposition models indicates that none of previous models could be successful in accurately predicting single-phase resistances of turbulent flow in inclined rod bundles. Therefore, a new superposition model to predict the single-phase pressure loss in inclined rod bundles is attempted to develop. First, two assumptions are proposed. One is that the flow resistance in the inclined rod bundle can be calculated by Eq. (1), the other one is that the crossflow mainstream velocity in the inclined rod bundle is not parallel to the positive direction of y axis. The lateral assumption is based on the fact that working fluids tend to flow into the space where the flow resistance is smaller. Correspondingly, a hypothetical average liquid level in the inclined rod bundle is proposed and plotted using the white line in Fig. 8 (a) and Fig. 8 (b). It can be concluded that the angle $\gamma$ between the average liquid level over the inclined rod bundle and the horizontal plane (black line in Fig.8 (a)) is zero due to the geometric symmetry of the y-z cross section. Therefore, $\beta$ is defined as the deflection angle between the average liquid level and the horizontal plane as shown in Fig. 8 (b). Then, the decomposition of velocity in the inclined rod bundle is shown in Fig.9. In addition, the inclined flow can be decomposed into the parallel flow and the horizontal flow, as shown in Fig. 10 and Fig. 11. The parallel component and the perpendicular component can be given by,

$$
\begin{aligned}
& V_{/ /, \infty}=\langle V\rangle_{\infty} \cos (\theta+\beta) \\
& V_{\perp, \infty}=\langle V\rangle_{\infty} \sin (\theta+\beta)
\end{aligned}
$$




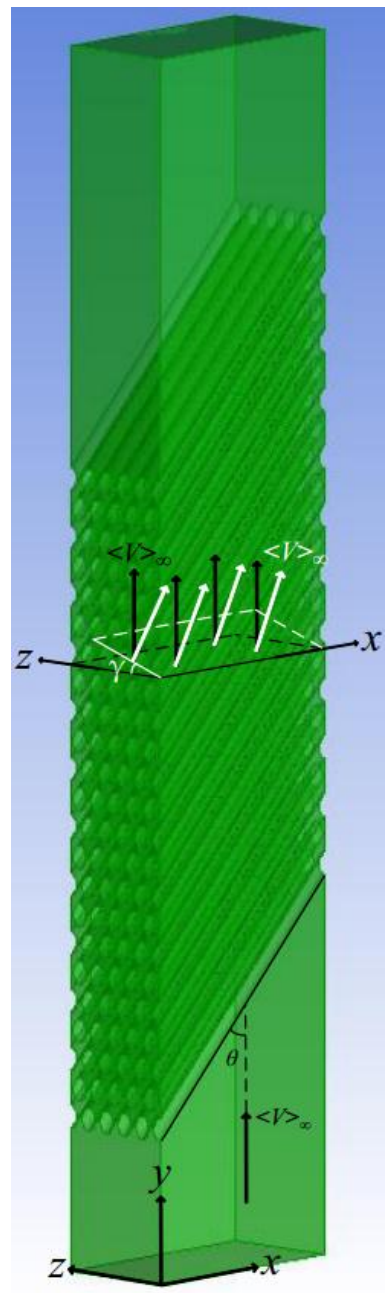

(a)

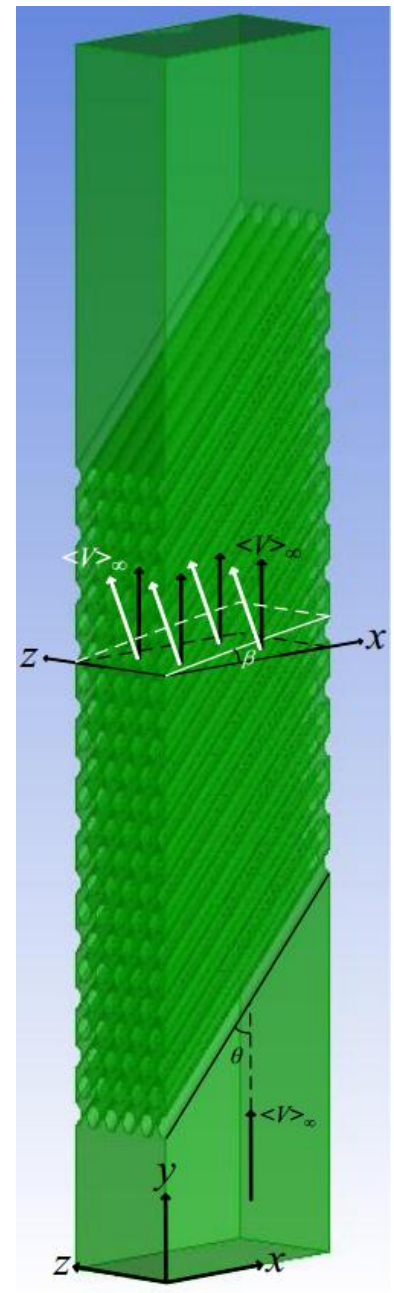

(b)

Fig.8. The hypothetical average liquid level.

The equivalent diameter in the parallel flow is defined as,

$\mathrm{D}_{e, /}=\frac{4\left(M \cdot \mathrm{S}_{\mathrm{L}} \cdot K \cdot S_{T}-\mathrm{M} \cdot K \cdot \frac{\pi}{4} d^{2}\right)}{2 \mathrm{M} \cdot \mathrm{S}_{\mathrm{L}}+\mathrm{M} \cdot K \cdot \pi d}$

Here, $K$ is the columns of the inclined rod bundle.

The average flow velocity in the parallel flow can be given by,

$$
\bar{V}_{/ /}=\frac{M \cdot S_{L} \cdot K \cdot S_{T}}{M \cdot S_{L} \cdot K \cdot S_{T}-M \cdot K \cdot \frac{\pi d^{2}}{4}} V_{/ /, \infty}
$$

Then the flow resistance in the parallel flow is given as follows:

$$
\Delta P_{/ /}=C_{/ /} \frac{b}{\sin \theta} \frac{1}{D_{/ /}} \frac{\rho_{F}{\overline{V_{/ 1}}}^{2}}{2}
$$

Here, $\mathrm{b}$ is the length in the direction of $\mathrm{x}$ axis for the inclined rod bundle. 
The equivalent diameter in the crossflow is the diameter of rods and the maximum flow velocity in the crossflow can be calculated by the following expression,

$$
V_{\perp}=\frac{M \cdot S_{T} \cdot b}{M \cdot\left(S_{T}-\pi d\right) \cdot b} V_{\perp, \infty}
$$

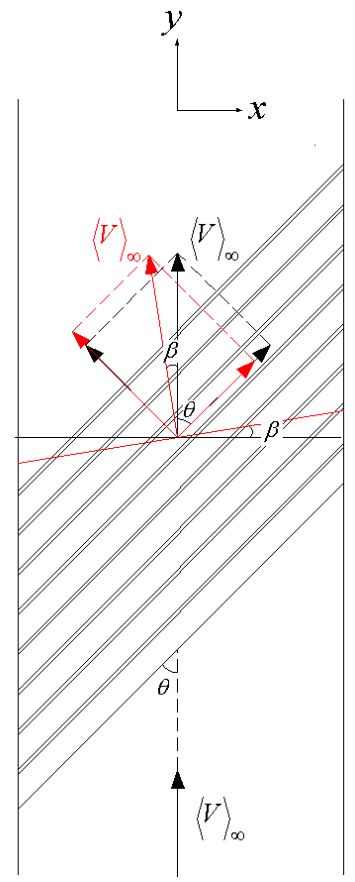

Fig.9. Decomposition of velocity in the new model.

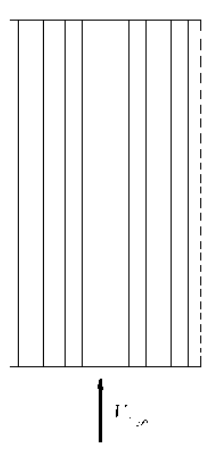

(a) The front view

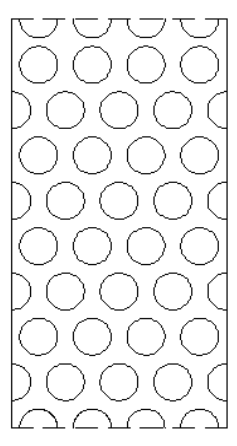

(b) The top View

Fig.10. The decomposed parallel flow. 


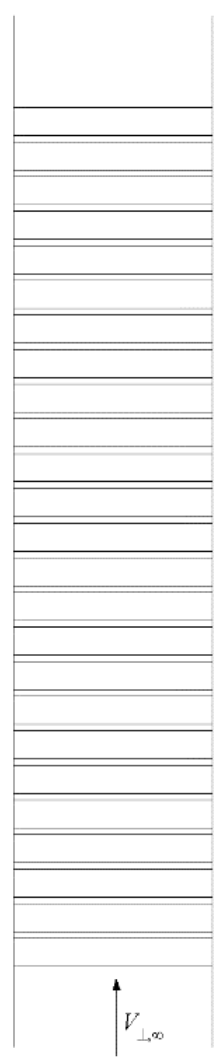

(a) The front view

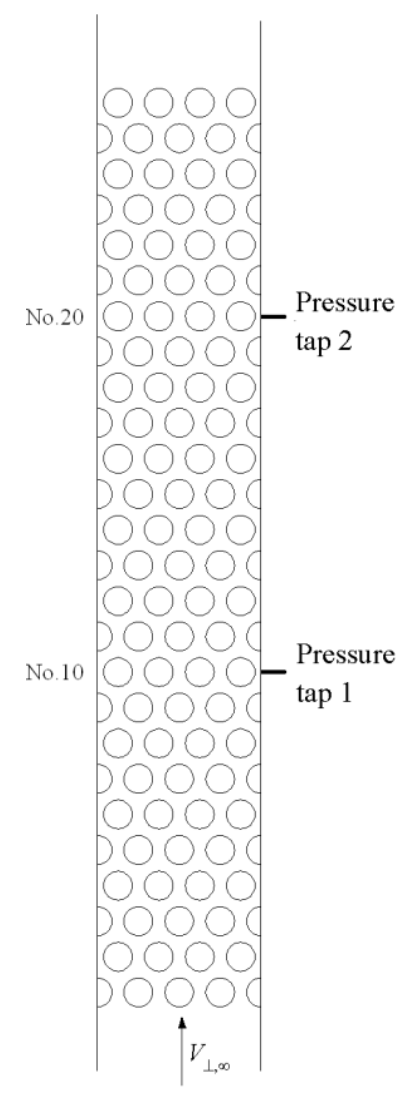

(b) The side view

Fig.11. The decomposed crossflow.

Then the flow resistance in the crossflow is given as follows:

$\Delta P_{\perp}=C_{\perp} M \frac{\rho_{F} V_{\perp}^{2}}{2}$

The comparison between predictions calculated by the new model and the experimental data in the present study is shown in Fig.12. The predictions are in good agreement with the pressure drop coefficient data in the inclined rod bundle for $17000<\langle\operatorname{Re}\rangle<43000$ when $\beta=9.0^{\circ}$.

In order to test the applicability of the new superposition model, the single-phase pressure drop coefficient data obtained by Choi et al. [11] were analyzed. The single-phase pressure loss coefficient data for $\theta=30^{\circ}$ were first investigated. Compared with the test data, the predictions calculated by the new model are obviously larger by the used of $\beta=9.0^{\circ}$ as shown in Fig.13. This suggests that the deflection angle for $\theta=30^{\circ}$ should be smaller than $9.0^{\circ}$, since form drag in 
the horizontal flow dominates in the total pressure loss for the inclined rod bundle. In fact, the best values of the deflection angle for various inclination angles are different, which are presented in Table 4. It's strange that the deflection angle for $\theta=45^{\circ}$ is larger compared with the deflection angles for $\theta=30^{\circ}$ and $\theta=60^{\circ}$. Why the deflection angle for $\theta=45^{\circ}$ is the largest?

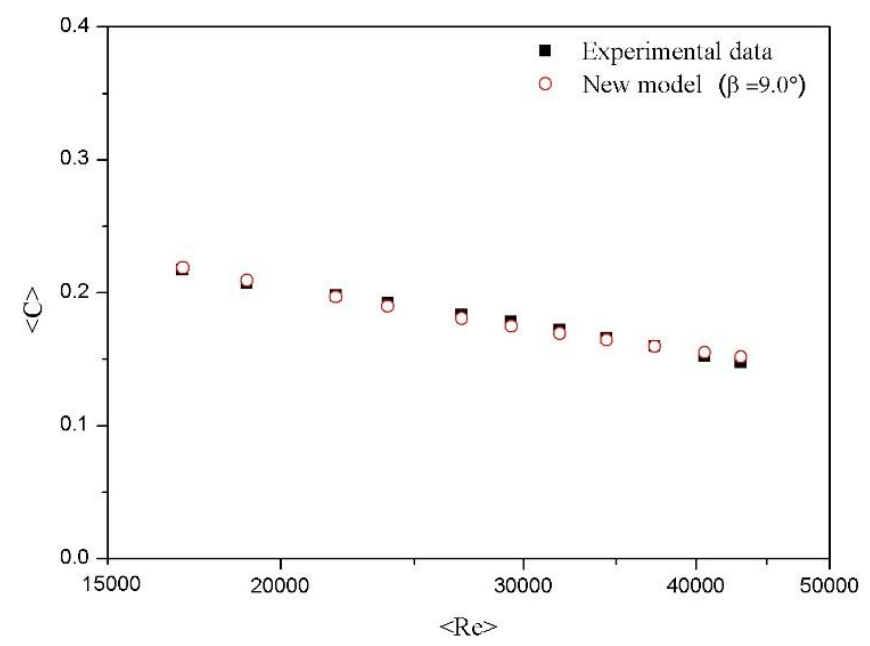

Fig.12. Predictions of pressure loss coefficient data in the present study.

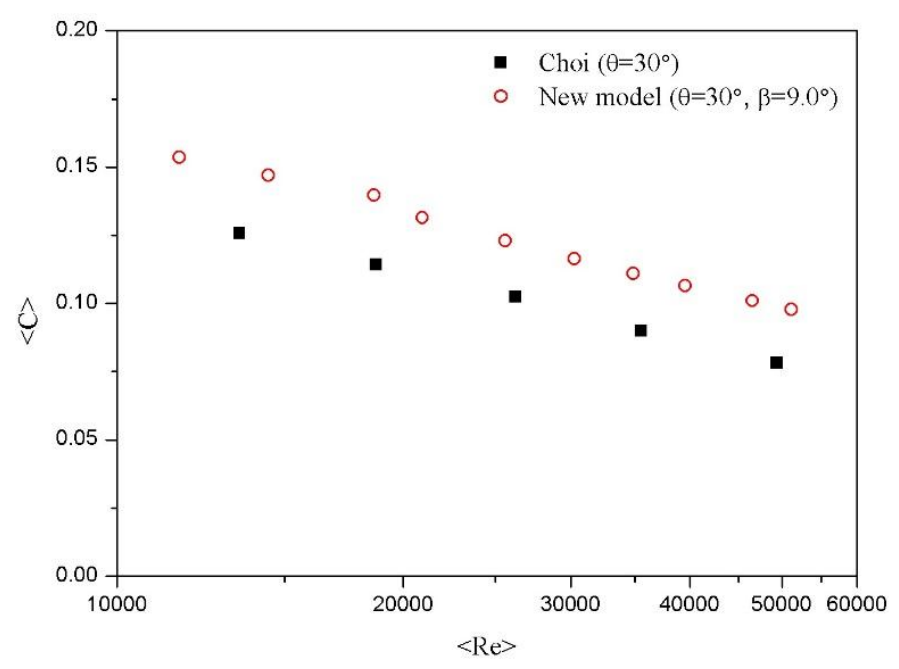

Fig.13. Predictions of pressure loss coefficients obtained by Choi (2002) for $\theta=30^{\circ}$ and $\beta=9.0^{\circ}$.

Table 4. Values of the deflection angle.

\begin{tabular}{|c|c|c|}
\hline Inclination angle (Degree) & Deflected angle (Degree) & Experiments \\
\hline 30 & 4.2 & Choi et al. [11] \\
\hline 45 & 9.0 & Present study, Choi et al. [11] \\
\hline 60 & 8.0 & Choi et al. [11] \\
\hline
\end{tabular}


In order to explain why the deflection angle for $\theta=45^{\circ}$ is the largest, it is speculated that deflection angles are mainly determined by three components: the dynamic pressure of working fluids, the gravity force and the form drag in the horizontal flow. It's not difficult to understand that the gravity force contributes to decreasing of the deflection angle. With decreasing the inclination angle for $45^{\circ} \leq \theta \leq 90^{\circ}$, the parallel component of the flow velocity in the inclined rod bundle increases, which contributes that working fluids tend to flow along the direction of the rod axis. In addition, the dynamic pressure of working fluids and the gravity force are relatively smaller compared with the form drag in the horizontal flow. Therefore, the form drag in the horizontal flow dominates and the deflection angle for $\theta=45^{\circ}$ is larger than that for $\theta=60^{\circ}$. However, though the parallel component of the flow velocity increases with decreasing the inclination angle for $0^{\circ} \leq \theta \leq 45^{\circ}$, the form drag of the horizontal flow for a given inlet velocity in the inclined test section decreases rapidly. As a result, the dynamic pressure of working fluids is not relatively smaller compared with the form drag in the horizontal flow and gradually dominates. Since the dynamic pressure of working fluids contributes to the decreasing of the deflection angle, the inclination for $\theta=30^{\circ}$ is smaller than that for $\theta=45^{\circ}$.

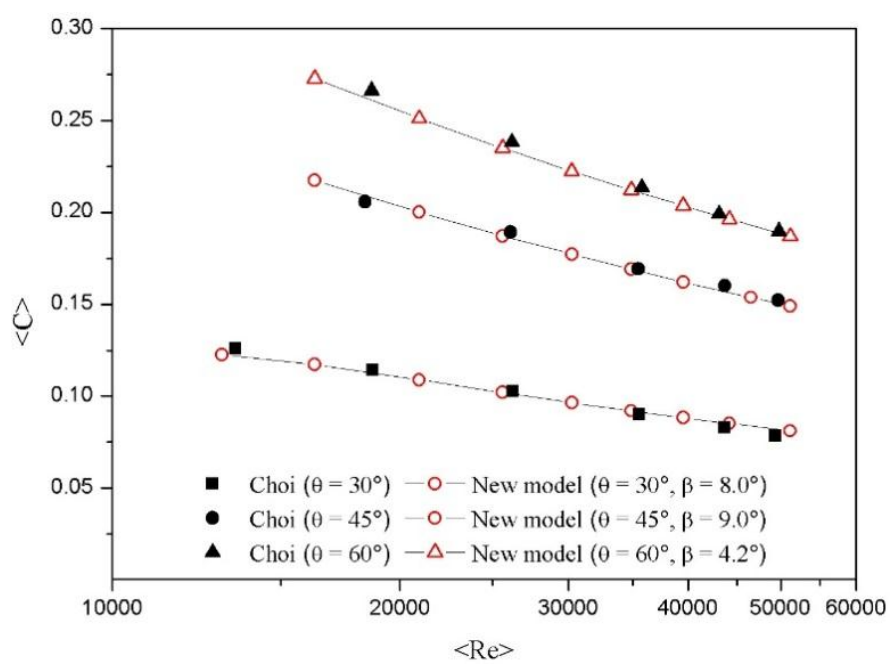

Fig.14. Predictions of pressure loss coefficients obtained by Choi et al. [11].

The predictions of single-phase pressure loss coefficients for various inclination angles using the new model are compared with experimental data obtained by Choi et al. [11] as shown in 
Fig.14. By using suitable values of deflection angles in Table 4, the new model is successful in predicting the test data. The deflection angles are plotted against the inclination angles as shown in Fig. 15. Deflection angles equal 0 degree for the vertical flow and horizontal flow. Since there are only the data in staggered inclined rod bundles for inclination angles equal $0,30,45,60$ and 90 degrees, the correlation for the deflection angle is difficult to develop. It is suggested that pressure drop experiments for more inclination angles should be investigated.

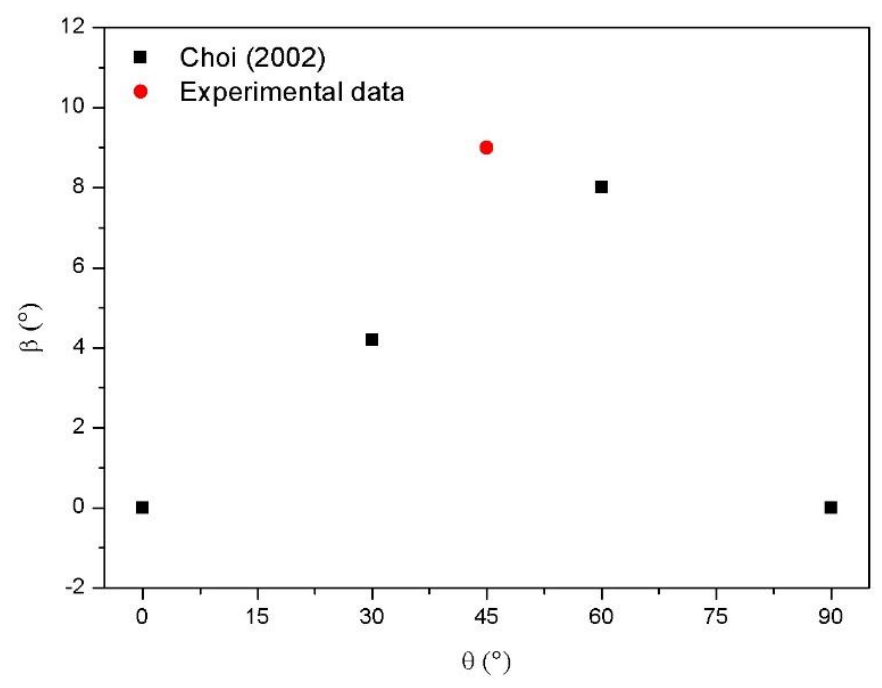

Fig.15. Values of the deflection angle for different inclination angles.

\subsection{Two-phase friction multiplier data}

The two-phase friction multiplier in the inclined rod bundle based on the liquid phase alone, $\Phi_{F}^{2}$, is defined as:

$$
\Phi_{F}^{2}=\frac{\langle\Delta P\rangle_{T P}^{F}}{\langle\Delta P\rangle_{F}}
$$

The two-phase flow friction pressure drop, $\langle\Delta P\rangle_{T P}^{F}$, is determined by the acceleration and gravitational pressure drop components subtracted from the total pressure drop. Since the temperature and pressure of the two-phase flow are almost kept constant in the test section, the density of the mixture can be considered as a constant value. Therefore, the acceleration pressure drop can be neglected. Furthermore, to calculate the two-phase gravitational pressure drop, it is necessary to obtain the void fraction, $\alpha$. In this study, Woldesemayat and Ghajar [20] correlation is employed and expressed in the following form, 


$$
\alpha=\frac{U_{G}}{U_{G}\left[1+\left(\frac{U_{F}}{U_{G}}\right)^{\left(\frac{\rho_{G}}{\rho_{F}}\right)^{0.1}}\right]+2.9\left[\frac{g d \sigma(1+\cos \theta)\left(\rho_{F}-\rho_{G}\right)}{\rho_{F}^{2}}\right]^{0.25}(1.22+1.22 \sin \theta)^{\frac{P_{a t m}}{P_{s y s}}}}
$$

Here, $U_{\mathrm{F}}$ and $U_{\mathrm{G}}$ are separately the superficial velocities of water and air. $\rho_{\mathrm{G}}$ is the density of air, $\sigma$ is the surface tension of water. $P_{\text {atm }}$ is the atmospheric pressure. $P_{\text {sys }}$ is the average pressure of inlet and outlet in the test section.

Many investigators have used a Martinelli-type model [21] to represent the two-phase friction multiplier in vertical or horizontal rod bunlde:

$$
\Phi_{F}^{2}=1+\frac{C}{\mathrm{X}_{t t}}+\frac{1}{\mathrm{X}_{t t}^{2}}
$$

where

$$
\mathrm{X}_{t t}=\left(\frac{1-x}{x}\right)^{0.9}\left(\frac{\rho_{G}}{\rho_{F}}\right)^{0.5}\left(\frac{\mu_{F}}{\mu_{G}}\right)^{0.1}
$$

Here, $C$ is a constant value. $X_{\mathrm{tt}}$ is Martinelli para meter. $x$ and $\mu_{\mathrm{G}}$ are mass quality and the dynamic viscosity of air.

The two-phase friction multiplier data in the inclined rod bundle are plotted against Martinelli parameter in Fig. 16. A strong mass velocity effect is observed. The two-phase friction multiplier increases with decreasing mass velocity at a given value of Martinelli parameter for $G \geq$ $200 \mathrm{kgm}^{-2} \mathrm{~s}^{-1}$. Therefore, the $\mathrm{C}$ factor is not constant for the inclined rod bundle. It's worth noting that though the mass velocity effect is considered in the $C$ factor, the two-phase friction multiplier data for $G<200 \mathrm{kgm}^{-2} \mathrm{~s}^{-1}$ are difficult to be fit well using Eq. (28). This is explained by the fact that the two-phase friction multiplier first increases and then decreases with increasing Martinelli parameter at a given value of mass velocity for $G<200 \mathrm{kgm}^{-2} \mathrm{~s}^{-1}$. As a result, to accurately predict the two-phase friction multiplier data, new models are needed and represented by the following expressions:

$$
\Phi_{F}^{2}=1+\frac{C_{1}}{X_{t t}^{C_{2}}}+\frac{1}{X_{t t}^{2}}
$$




$$
\Phi_{F}^{2}=1+\frac{C_{4}}{X_{t t}^{0.35}}-\frac{3.2}{X_{t t}^{2}}-\frac{0.7}{X_{t t}^{3}}+\frac{0.125}{X_{t t}^{4}}
$$

Here, $C_{1}, C_{2}$ and $C_{4}$ are valuables with respect to mass velocities. Eq. (30) and Eq. (31) are usable for $G \geq 200 \mathrm{kgm}^{-2} \mathrm{~s}^{-1}$ and $G<200 \mathrm{kgm}^{-2} \mathrm{~s}^{-1}$, respectively. A dimensionless mass velocity $C_{3}$ is defined as follows,

$C_{3}=G / G^{*}$

where $G^{*}$ is a constant value of $200 \mathrm{kgm}^{-2} \mathrm{~s}^{-1}$.

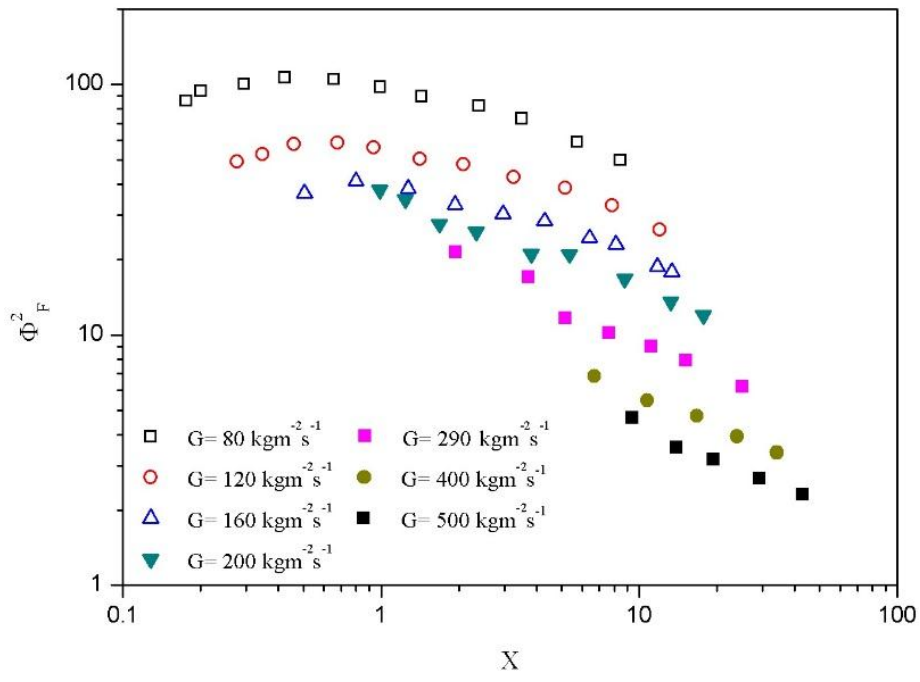

Fig.16. Two-phase friction multiplier data as a function of Martinelli parameter.

The best values of $C_{1}, C_{2}$ and $C_{4}$ factors for $C_{3}$ factors are exhibited in Table 5. When the corresponding values of $C_{1}, C_{2}$ and $C_{4}$ factors are employed, the predictions are in good agreement with the two-phase friction multiplier data as shown in Fig. 17.

Table 5. Values of $C_{1}, C_{2}, C_{3}$ and $C_{4}$ factors for various mass velocities.

\begin{tabular}{|c|c|c|c|c|}
\hline$G\left(\mathrm{kgm}^{-1} \mathrm{~s}^{-2}\right)$ & $C_{1}$ & $C_{2}$ & $C_{3}$ & $C_{4}$ \\
\hline 80 & ----- & ----- & 0.4 & 100 \\
\hline 120 & ----- & ----- & 0.6 & 62 \\
\hline 160 & ----- & ----- & 0.8 & 43 \\
\hline 200 & 39 & 0.45 & 1 & ----- \\
\hline 290 & 28.5 & 0.53 & 1.45 & ----- \\
\hline 400 & 20.5 & 0.62 & 2 & ----- \\
\hline 500 & 17 & 0.70 & 2.5 & ----- \\
\hline
\end{tabular}




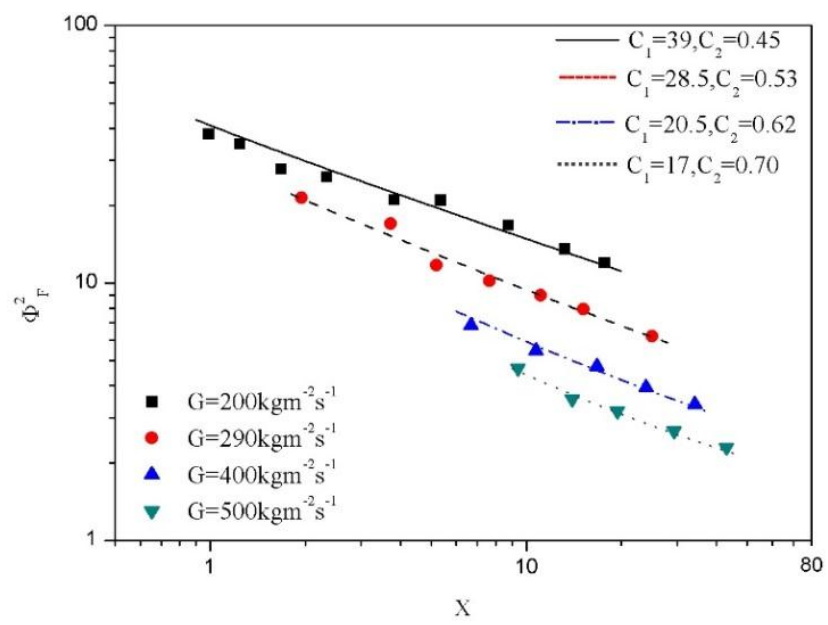

(a) $G \geq 200 \mathrm{~kg} /\left(\mathrm{m}^{2} \mathrm{~s}\right)$.

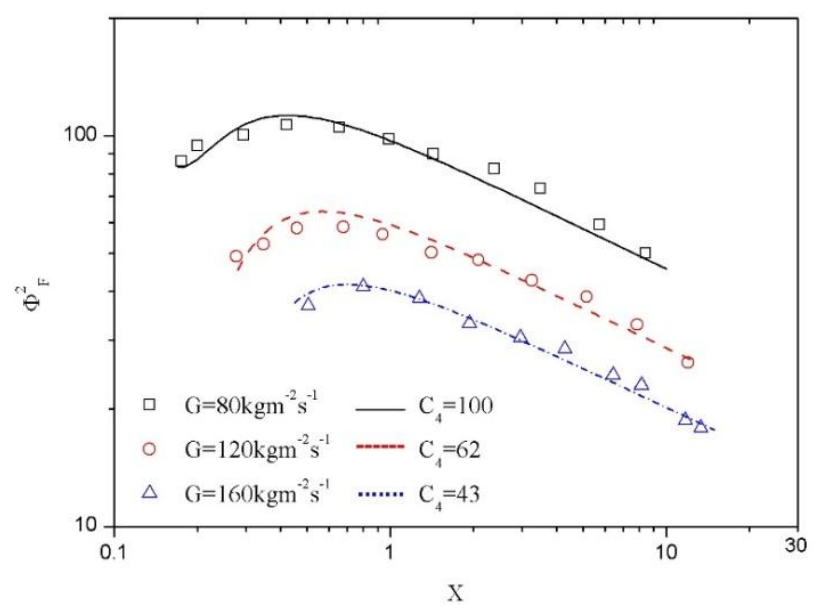

(b) $G<200 \mathrm{~kg} /\left(\mathrm{m}^{2} \mathrm{~s}\right)$.

Fig.17. Comparison between the experimental data and predictions.

Then the best values of $C_{1}, C_{2}$ and $C_{4}$ factors are plotted against Martinelli parameter as shown in Fig. 18. When the total mass velocity increases, $C_{1}$ factor and $C_{4}$ factor decrease while $C_{2}$ factor increases approximately linearly. Based on the present data, new correlations to predict $C_{1}, C_{2}$ and $C_{4}$ factors can be expressed as follows,

$$
\begin{aligned}
& C_{1}=39 / C_{3}^{0.9} \\
& C_{2}=0.17 \times C_{3}+0.28 \\
& C_{4}=32 / C_{3}^{1.25}
\end{aligned}
$$

As a result, the expressions for predicting the two-phase friction multiplier in the inclined rod bundle are successful in estimating $95 \%$ of the data points considered, within $\pm 15 \%$. Fig. 19 represents the ratios of the predictions to the experimental two-phase friction multiplier. 


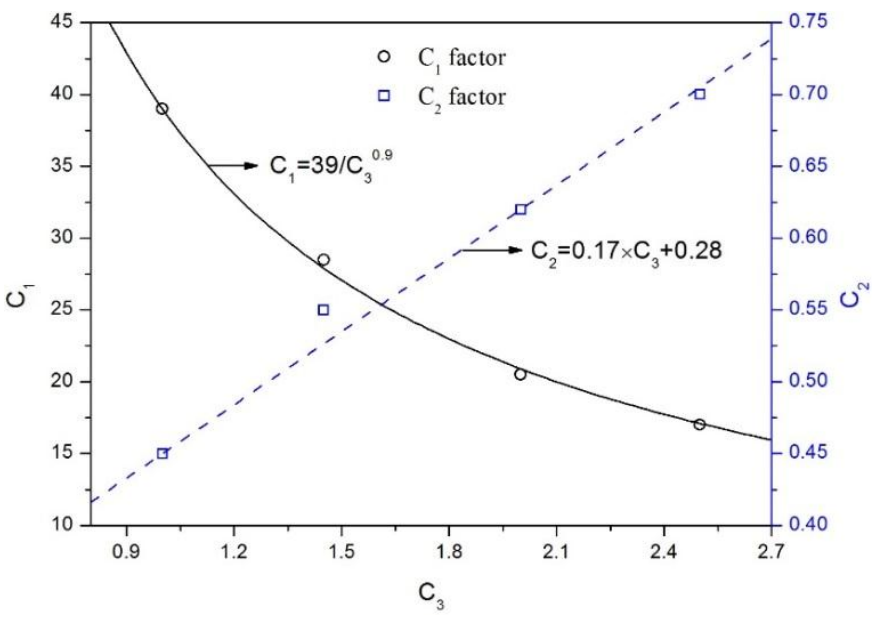

(a) $C_{1}$ and $C_{2}$ factors for $G \geq 200 \mathrm{~kg} /\left(\mathrm{m}^{2} \mathrm{~s}\right)$.

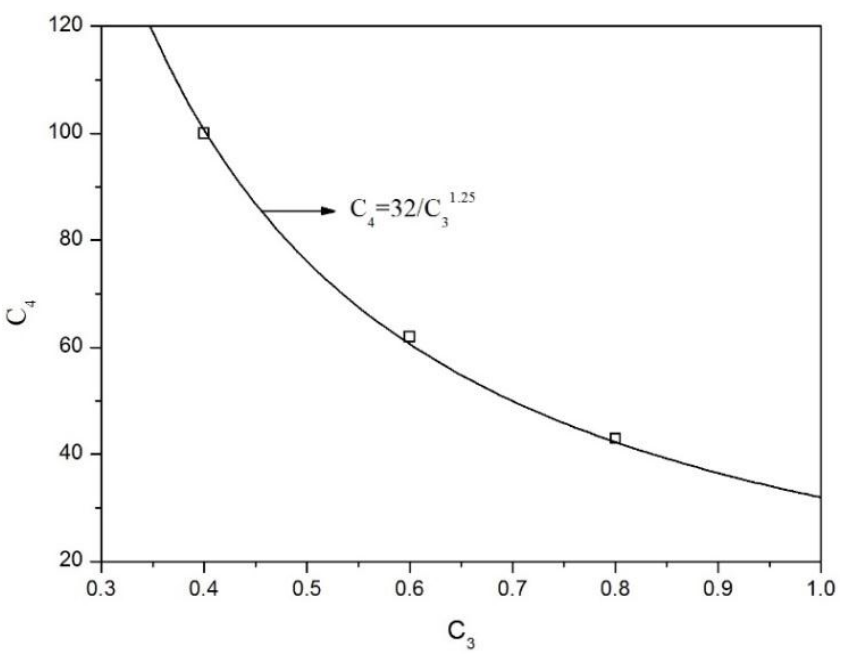

(b) $C_{4}$ factor for $G<200 \mathrm{~kg} /\left(\mathrm{m}^{2} \mathrm{~s}\right)$.

Fig. $18 \mathrm{C}_{1}, \mathrm{C}_{2}$ and $\mathrm{C}_{4}$ factors as a function of $\mathrm{C}_{3}$

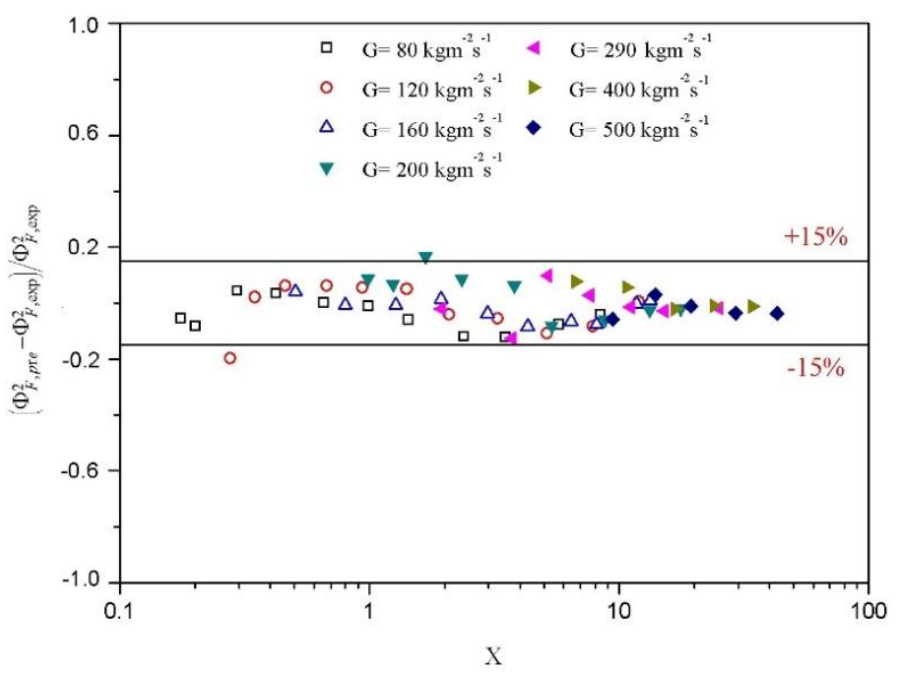

Fig.19. Deviations between the experimental data and predictions.

\section{Conclusions}


Pressure drop experiments for vertically upward single-phase water and two-phase air-water flow across staggered rod bundles having inclination angles of 0,45 and 90 degrees were conducted. A superposition model and new correlations were developed to predict the single-phase pressure loss coefficients in inclined rod bundles. The present data and the experimental data in previous experiments of other researchers were also compared with the predictions computed by the new superposition model. New correlations were developed to be successful in predicting the two-phase pressure drop in the inclined rod bundle. The following specific conclusions can be drawn from this study:

1. The new superposition model is able to accurately predict single-phase pressure loss coefficients in inclined rod bundles using the suitable values of deflection angles for different inclination angles. However, since there are only the data in staggered inclined rod bundles for inclination angles equal $0,30,45,60$ and 90 degrees, it is suggested that pressure drop experiments for more inclination angles should be investigated to develop correlations of deflection angles.

2. The two-phase friction multiplier in the inclined rod bundle can be fit well in terms of Maritnelli parameter and the defined dimensionless mass velocity.

3. Strong mass velocity effects were observed for the two-phase friction multiplier in the inclined rod bundle. For a given Maritnelli parameter, the two-phase friction multiplier in the inclined rod bundle decreases with increasing mass velocity. In addition, the two-phase friction multiplier first increases and then decreases with increasing Martinelli parameter at a given value of mass velocity for $G<200 \mathrm{kgm}^{-2} \mathrm{~s}^{-1}$.

\section{Acknowledgements}

This work is supported by the Program for Changjiang Scholars and Innovative Research Team in University (No. IRT1280) funded by the ministry of Education, China. The authors would also express their thanks to National Science Foundation of China (Grant No. Project 11575137).

\section{References}

[1] T. Cong, W. Tian, S. Qiu, G. Su, Study on secondary side flow of steam generator with coupled heat transfer from primary to secondary side, Applied Thermal Engineering, 61 (2013) 519-530. 
[2] T. Cong, W. Tian, G. Su, S. Qiu, Y. Xie, Y. Yao, Three-dimensional study on steady thermohydraulics characteristics in secondary side of steam generator, Progress in Nuclear Energy, 70 (2014) 188-198.

[3] T. Cong, R. Zhang, W. Tian, S. Qiu, G. Su, Effects of power level on thermal-hydraulic characteristics of steam generator, Progress in Nuclear Energy, 81 (2015) 245-253.

[4] C. Wang, T. Cong, S. Qiu, W. Tian, Y. Wu, G. Su, Numerical prediction of subcooled wall boiling in the secondary side of SG tubes coupled with primary coolant, Annals of Nuclear Energy, 63 (2014) 633-645.

[5] A. Serizawa, K. Huda, Y. Yamada, I. Kataoka, Experiment and numerical simulation of bubbly two-phase flow across horizontal and inclined rod bundles, Nuclear engineering and design, 175 (1997) 131-146.

[6] F. Kazakevich, Influence of the angle of approach of a gas stream on the aerodynamic resistance of a tube bundle, Izv. Vses. Teploteckh. Inst. Imoni. FE Dzerzkinkogo No. 8, (1952) 7-12.

[7] H. Boettgenbach, Messungen von Stroemungsfeldern in engen Stabbundeln zur Ueberprufung einer anisotropen Stroemungsfwlt theorie, Koktrorarbeit Ruhr-Universitat, Bocum, (1977).

[8] S. Möller, Un modelo constitutivo para O escoamento atraves de um attanjo de barras de secao circular, in, Universidade Federal de Rio de Janeiro, 1979.

[9] H. Groehn, Thermal hydraulic investigation of yawed tube bundle heat exchangers, Advanced Study Institute on Heat Exchangers ASI Proceedings, Istanbul, (1981).

[10] N. Todreas, Hydrodynamics of single-and two-phase flow in inclined rod arrays, in, Massachusetts Inst. of Tech., Cambridge (USA), 1984.

[11] S.-K. Choi, I.K. Choi, K.Y. Lee, H.Y. Nam, J.H. Choi, H.K. Choi, Measurement of Pressure Drop in Inclined Triangular and Rotated Triangular Tube Bundles, in: ASME 2002 Pressure Vessels and Piping Conference, American Society of Mechanical Engineers, 2002, pp. 63-70.

[12] I. Idel'chik, Handbook of Hydraulic Resistance, Coefficients of Local Resistance and of Friction, 1960, English version, AEC-TR-6630, (1966).

[13] D. Liles, TRAC-P1: An advanced best estimate computer program for PWR LOCA analysis. I. Methods, Models, User Information and Programming Details, in, NUREG/CR-0063, LA-7279-MS, 1978.

[14] Y. Coëffe, N. Todreas, Formulation of the fluid-solid interaction force for multi-dimensional, two-phase flow within tube arrays, Nuclear Engineering and Design, 58 (1980) 383-391.

[15] M. Barasch, The measurement of two-dimensional phase separation phenomena, The Commission, 1981.

[16] M. Osakabe, H. Adachi, Characteristic of Two-phase Slanting Flow in Rod Bundle, Journal of Nuclear Science and Technology, 19 (1982) 504-506.

[17] Z. Meng, B. Dong, L. Wang, X. Fu, W. Tian, Y. Yang, G. Su, Experimental research of liquid entrainment through ADS-4 in AP1000, Annals of Nuclear Energy, 72 (2014) 428-437.

[18] P. Grillo, G. Mazzone, Single-and two-phase pressure drops on a $6 \times 6$ rod bundle at 70 atm, Nuclear Technology, 15 (1972) 25-35.

[19] R. Dowlati, A. Chan, M. Kawaji, Hydrodynamics of two-phase flow across horizontal in-line 
and staggered rod bundles, Journal of fluids engineering, 114 (1992) 450-456.

[20] M.A. Woldesemayat, A.J. Ghajar, Comparison of void fraction correlations for different flow patterns in horizontal and upward inclined pipes, International Journal of Multiphase Flow, 33 (2007) 347-370.

[21] R. Lockhart, R. Martinelli, Proposed correlation of data for isothermal two-phase, two-component flow in pipes, Chem. Eng. Prog, 45 (1949) 39-48. 